UNIVERSITA' DEGLI STUDI DI BERGAMO

DIPARTIMENTO DI INGEGNERIA GESTIONALE

QUADERNI DEL DIPARTIMENTO ${ }^{\dagger}$

Department of Economics and Technology Management

Working Paper

n. $02-2011$

Best practices in demand forecasting: tests of universalistic, contingency and configurational theories

by

Matteo Kalchschmidt

† Il Dipartimento ottempera agli obblighi previsti dall’art. 1 del D.L.L. 31.8.1945, n. 660 e successive modificazioni. 


\section{NOTE}

I Working Papers della Collana dei Quaderni del Dipartimento di Ingegneria Gestionale costituiscono un servizio atto a fornire la tempestiva divulgazione dei risultati dell'attività di ricerca, siano essi in forma provvisoria o definitiva.

I Working Papers della Collana sono pubblicati nell'archivio istituzionale dell'Università degli studi di Bergamo (Aisberg): http://dspace-unibg.cilea.it/handle/10446/370. 


\title{
Best practices in demand forecasting: tests of Universalistic, Contingency and Configurational Theories
}

\author{
Matteo Kalchschmidt ${ }^{\dagger}$
}

Department of Economics and Technology Management - Università degli Studi di Bergamo

\begin{abstract}
While the literature on demand forecasting has examined the best practices in the field, the interpretation and definition of best practices can be difficult due to the different perspectives that the literature has adopted. First, a universalistic perspective can be considered because some specific practices are really best regardless of the context, the forecasting problems, etc. Some other contributions have also taken a contingent approach, which states that best practices depend on the specific kind of company considered or the forecasting scenario. A third potential perspective is the configurational one, which asserts that best practices depend on a set of factors. In this work, we plan to study which of these perspectives really holds true and to what extent they do so. Analysis is conducted by collecting data of more than 500 companies in different countries via the GMRG IV questionnaire. The impact of forecasting is studied in terms of operational performance by designing and testing different sets of propositions that underline the three aforementioned perspectives.
\end{abstract}

Keywords: forecasting, GMRG, universalistic theory, contingency theory, configuration theory

\footnotetext{
${ }^{\dagger}$ Corresponding author Viale Marconi 5, 24044 Dalmine (BG) Italy, tel + 39.035.205.2360 email matteo.kalchschmidt@unibg.it
} 


\section{INTRODUCTION}

Sales forecasting is an important task given its impact on decisions at many different levels within firms. During the last few decades, many researchers have provided new forecasting methods and techniques with the goal of improving forecast accuracy (Wright et al., 1986; Armstrong, 2001). For years, the primary purpose of researchers and practitioners in the forecasting field has been to help companies by providing them with sophisticated quantitative approaches reduce forecasting errors. As a result, we have witnessed a surge in the development of new forecasting methods.

Several researchers, however, have provided evidence that forecasting accuracy is not always higher when complex rather than simple techniques are used (Mentzer and Cox, 1984; Dalrymple, 1987; Sanders and Manrodt, 1994; Lawrence et al., 2000, Dekker et al. 2004). These authors have suggested that more sophisticated forecasting techniques alone do not necessarily improve accuracy. Managers should also consider other issues associated with the management of the forecasting process (Mentzer and Cox, 1984). Many studies have analyzed other areas of improvement for the forecasting process (Mentzer and Kahn, 1997; Mentzer and Bienstock, 1998; Chaman, 1999; Chase, 1999). Among the most cited, inter-functional integration (Mentzer and Bienstock, 1998; Helms et al., 2000), information management (Mentzer and Khan, 1997; Mentzer and Bienstock, 1998; Moon and Mentzer, 1998) and a clear definition of a forecasting process (Mentzer and Bienstock, 1998; Mentzer et al., 1999; Chaman, 2001) have been considered critical to greater forecasting accuracy.

Specific attention has been paid by some authors companies' behavior in terms of the actual forecasting process. This has led to the development of a research area related to the study of forecasting practices, i.e., the investigation of what companies are actually practicing. The literature provides several survey-based studies on forecasting practices (e.g., Cerullo et al., 1975; Dalrymple, 1987; Reyna et al., 1991; Sanders and Mandrot, 1994; Mentzer and Kahn, 1997; Mady, 2000; McCarthy et al., 2006; Zotteri and Kalchschmidt, 2007). In particular, scholars have paid attention to what companies should do, and thus the literature has been deeply concerned with the identification of which practices lead to better performance. Some researchers have examined the use of forecasting techniques and their impact on forecasting accuracy. However, others have also focused on organizational issues and forecasting use (Watson, 1996; Winklhofer and Diamantopoulos, 1997; Hughes, 2001; Chaman, 2004) as well as information management (Armstrong, 2001; Winklhofer and Diamantopoulos, 2002). The different contributions on this topic, however, applied different perspectives while interpreting companies' behaviors. Some contributions adopted universalistic perspectives 
and argued for a "pure best practice" approach in forecasting. For example, Armstrong (2001) provided principles that should be applied in the different phases of the forecasting process; Fildes and Goodwin (2007) listed eleven principles that show how forecasters should use judgment in forecasting. Under the universalistic perspective, optimal solutions guiding company behavior exist.

A second group of researchers has adopted a contingency perspective. Contingency theory argues that, in order to be effective, the forecasting process must be adapted to the company's situation. Some authors have considered, for example, size (e.g., Peterson, 1993; Winkholfer and Diamantopoulos, 1997) or uncertainty (e.g., Sanders and Manrodt, 1994) as contingent factors.

A third group of scholars has developed arguments that are consistent with a configurational approach. Configuration theory differs from universalistic and contingency theories in that configuration theory bases itself on typologies of ideal types and explicitly adopts the systems assumption of "equifinality" (Delery and Doty, 1996). In general, configuration theory is concerned with how a pattern of multiple variables is related to a dependent variable rather than with how the individual variables are related to a dependent one. For example, Moon et al. (2003) proposed a framework in which four stages of effectiveness are defined: according to the level of functional integration, the forecasting approach, the systems in place and the performance measurement.

To date, the literature has analyzed forecasting practices under the light of different theoretical backgrounds. This work aims to contribute to the debate surrounding forecasting practices by either providing evidence of the extent to which universalistic best practices exist or the extent to which best practices depend on the context from which companies operate. Providing contributions in this direction would allow companies to understand how they should design their forecasting solutions and to determine to what extent best forecasting practices are imitable. Because different contributions have been based on different research protocols and samples, there has been a lack of evidence, as it is very difficult to assess to what extent the data under consideration is responsible for a specific result. No contribution has yet compared the different perspectives at the same time with the same data to evaluate the applicability of the different perspectives. This work aims to fill this specific gap. To achieve this goal, this article will compare these three theoretical perspectives to evaluate the relative importance of each in explaining the relationship between companies' forecasting methods and their respective performances. To do so, we will first take into account the literature on forecasting practices to identify the extent to which existing contributions have 
provided evidence of the different perspectives. We will then generate propositions that are consistent with the three different perspectives and empirically test them via the GMRG IV dataset. In the end, we will provide a discussion of the results and draw general conclusions from the discussion.

\section{LITERATURE REVIEW}

Within the forecasting literature, various researchers have studied companies' behaviors from specific points of view: which methods they have adopted, what information they have collected, in which organizational unit forecasting was managed, etc. Despite this narrow focus, however, much of the literature is descriptive and presents practices that successful companies already have in place. These studies focus on specific industries or countries. For example, Watson (1996) focused on forecasting in the Scottish electronics industry, while Mentzer and Kahn (1997) provided evidence on practices within 207 US companies. Hughes (2001) focused attention on organizational topics using data collected from 81 UK companies and highlighted the main barriers to proper forecasting. Similarly, Chaman (2004) investigated US companies, Duran and Flores (1998) analyzed forecasting practices in Mexican firms, Klassen and Flores (2001) focused their attention on Canadian companies and Mady (2000) studied Egyptian firms. Mentzer and Cox (1984) surveyed 160 companies to understand the degrees of familiarity and satisfaction for various forecasting approaches. Similar contributions have been provided by Diamantopoulos and Winkholfer (1999).

Several of these works, in addition to the simple description of companies' behaviors, have also analyzed the extent to which specific practices have been adopted. Typically, most researchers focused on practices that have been deemed successful by the current literature, which has led to the modern notions of best practices.

The literature in several disciplines has always devoted attention to identifying and disseminating best practices. Laugen et al. (2005) summarize as follows:

The basic principle of the best practice thinking is that operations philosophies, concepts and techniques should be driven by competitive benchmarks and business excellence models to improve an organization's competitiveness through the development of people, processes and technology. (p. 132)

Existing contributions focusing on the best practice paradigm have analyzed the impact of specific practices on performance. As a result, past research has focused on identifying and studying what the best performers do in order to disseminate those practices among the rest of the business world. 
The best practice paradigm has been typically analyzed under three different perspectives: universalistic, contingency and configurational. These perspectives have been used to study best practices in several disciplines, such as manufacturing systems (Ketokivi and Schroeder, 2004), new product development (McCarthy et al., 2006) and human resource management (Delery and Doty, 1996).

In the universalistic perspective, best practices are deemed those practices that lead to better performances regardless of which companies are considered and in which contexts they are operating. Researchers taking this perspective believe that some practices are always better than others and that all organizations should adopt these practices (Dewar and Werbel, 1979). Their works typically offer extensive knowledge framed by specific rules or principles that companies can understand and apply to their own forecasting processes. For example, Armstrong (2001) provided principles that should be applied in the different phases of the forecasting process, and Fildes and Goodwin (2007) listed eleven principles that show how forecasters should use judgment in forecasting.

In addition to this universalistic perspective, some contributions in different fields show that the relationship between best practice and performance is not completely straightforward (Powell, 1995; Laugen et al., 2005). In particular, Voss (2005) suggested that the use of best practices should be investigated within a specific context because the impact of best practices (and their applicability in general) depends on the specific context under investigation (Powell, 1995; Sousa and Voss, 2001 and 2008; Ketokivi and Schroeder, 2004). For this reason, in the forecasting literature, many authors have also taken a contingent approach by analyzing how practices change according to specific independent variables. Firm size is often considered a major factor (Peterson, 1993; Winkholfer and Diamantopoulos, 1997; Peterson and Jun, 1999; Sanders and Manrodt, 1994). Other researchers have investigated industry type (Sanders, 1992), uncertainty and environmental turbulence (Sanders and Manrodt, 1994; Diamantopoulos and Winkholfer, 1999; Watson, 1996). While great attention has been paid to the effect of environmental variables on forecasting performance and practices, other authors have analyzed which practices are more effective than others (Kahn and Mentzer, 1994; Wacker and Sprague, 1995, 1998). Their contributions have provided evidence that specific practices may perform differently in different contexts; for example, judgmental techniques can be very effective in uncertain contexts, while the same techniques can be less effective when several products need to be forecasted (Diamantopoulos and Winkholfer, 1999).

Other scholars have taken a configurational perspective instead. In general, configurational theories are concerned with how the pattern of multiple independent variables is related to a 
dependent variable rather than with how individual independent variables are related to a dependent variable. Thus, researchers focus on the identification of configurations (i.e., "ideal-types") that represent internally and externally coherent solutions, which companies should refer to for their own practices. The contingent and configurational perspectives are most likely related, as similar contingency variables may influence different practices at the same time. Consequently, companies in different contexts may utilize different configurations for their forecasting processes. However, other scholars have noted that configurations may explain differences better than contingencies can (e.g., Ketokivi and Schroeder, 2004). This result has been found, for example, in the manufacturing strategy field (e.g., Bozarth and McDermott, 1998).

Some scholars have suggested that forecasting can be analyzed by looking directly at the overall picture, i.e., referring to specific combinations of variables (Armstrong, 1987; Fildes and Hastings, 1994; Mentzer et al., 1999). Mentzer et al. (1999) and Moon et al. (2003) suggested that forecasting models can be analyzed by utilizing four specific stages of development that represent the ideal models as reference points. Zotteri and Kalchschmidt (2007) argued that forecasting practices tend to be correlated because companies adopt consistent practices and that contingent factors only partially explain these relationships.

Although the literature provides evidence that supports all three perspectives, there is no clear understanding of the explicative power of the three underlying theories in this forecasting case. Danese and Kalchschmidt (2010a and 2010b) have partially addressed this topic, as they have analyzed both individual practices (i.e., the universalistic perspective) and some of their interactions with other practices (an approach similar to the configurational perspective). Limited evidence can be found in these works regarding the contingency perspective because only demand variability was considered a control variable. Furthermore, in Danese and Kalchschmidt (2010b), the configuration perspective was not fully considered, as only the interaction effects among forecasting practices were taken into account. In this work, we plan to provide a structured and extensive comparison of the three different perspectives to assess their respective explicative powers. We specifically plan to extend and complete Danese and Kalchschmidt's (2010a and 2010b) contributions in two ways: first, by introducing the missing contingency perspective; and second, by analyzing contributions that have adopted configurational theory and thus explicitly testing the configurational perspective. 


\section{RESEARCH OBJECTIVES AND METHODOLOGY}

\section{Research objectives}

Based on the previously described literature, this works plans to compare the different perspectives underlining the interpretations of best practices in forecasting. To do so, we need to determine what best practices by comparing the different practices with specific performance measures. The existing literature considers accuracy as the most relevant performance metric in the forecasting process (Mentzer and Bienstock, 1998; Chase, 1999). However, several difficulties arise when accuracy is utilized to compare different companies' performances. First, not all companies measure accuracy in the same way, and standardizing all the different measures of accuracy is a difficult task. Second, controlling for the internal environment can also be very difficult, which means that a similar forecast error in different contexts may have very different impacts. Finally, this work utilizes survey data, which makes comparisons among companies more complex due to the different contexts in which companies operate.

For these reasons, previous contributions have considered other performance measures to identify best practices. Some studies point out that reorganizing the forecasting process can also have a direct impact on cost and delivery performances (McCarthy and Golicic, 2002; Småros, 2007; Danese and Kalchschmidt, 2010a, 2010b). In this work, we will study the impact of reorganization on both cost and delivery performances.

To compare the different perspectives, we proceeded as follows: we defined specific research propositions that are consistent with the three different perspectives by relying on previous literature. More specifically, we designed one set of proposition for each perspective. We then tested each proposition using the same sample of data and evaluated whether each proposition was supported or not. We assumed that support for a specific proposition suggested support for the underlying perspective. A similar approach had been applied previously by Delery and Doty (1996).

The existing literature provided some contributions that are consistent with the universalistic perspective. Scholars have often suggested that using forecasting techniques allows companies to increase performance because the techniques reduce judgmental bias and the effects of irrelevant information (Makridakis et al., 1998) that are often associated with opinion-based forecasts. Several researchers have noted that information on the market collected internally and externally from the customers can help companies better comprehend future market dynamics (Helms et al., 2000). By knowing their customers' sales plans in advance, manufacturers can have more confidence about what will happen in the future, 
which allows companies to better plan their production cycles (Stalk and Haut, 1990). Similarly, incorporating information on market research and current economic conditions into the forecasting process allows companies to analyze the latest market trends and the impact of new product launches and promotions, which further reduces demand uncertainty and increases comprehension of market dynamics (Helms et al., 2000). Perceived demand uncertainty can be further reduced, and comprehension of market dynamics can be further increased if information about the market comes from multiple sources and data is interpreted with the help of forecasting techniques. The cumulative effect of forecasting techniques is better planning of production, which in turn leads to reduced manufacturing and production costs.

In addition, the forecasting process can have an impact on companies' cost performances. More specifically, when decision-making processes are not based on a single forecast, islands of analysis will appear within a company. As a result, organizational units will not align their plans and actions, which may create misinformation, inefficiency and excess inventory (Stevens, 1989; Triantis, 2002). Taking into consideration the abovementioned theory in conjunction with the universalistic theory, we formulate the following research propositions:

RPla: The use of forecasting techniques is positively related to operational performance

RPIb: The use of information in the forecasting process is positively related to operational performance

RP1c: The use of forecasting techniques in decision-making processes is positively related to operational performance

With regard to the contingent perspective, some scholars note the impact of context on forecasting performance. The existing literature has highlighted different variables that may influence the impact of forecasting on performance. One is demand variability, which is usually considered a key issue in selecting the forecasting approach (e.g., Sanders and Manrodt, 1994; Bartezzaghi and Verganti, 1995; Sanders and Ritzman, 1995; Watson, 1996; Diamantopoulos and Winkholfer, 1999; Armstrong, 2001; Danese and Kalchschmidt, 2010a, 2010b). For example, McCarthy et al. (2010) explained that environmental velocity (i.e., the rate and direction of industry changes) forces companies to process information differently to 
make more effective decisions. Other key factors are the type of industry (Peterson, 1990; Sanders, 1992; Kahn and Mentzer, 1995) and the kind of production system adopted. In fact, when production is based primarily on Engineering to Order or Make to Order systems, forecasting is mainly used to plan procurement and capacity; thus, forecasting accuracy in these situations has a different impact compared to forecasting accuracy in Make to Stock situations (e.g., Wisner and Stanley; 1994). Other scholars have shown that the complexity of the forecasting problem may influence how the process is conducted. For instance, if forecasting has to be conducted for several products or product lines, companies may prefer to adopt quantitative approaches rather than judgmental ones (Zotteri and Kalchschmidt, 2007). Other researchers have considered forecasting technique familiarity to be an important variable, as it may affect the ability to effectively adopt specific approaches (Mentzer and Cox, 1984; Mentzer and Kahn, 1995). Cultural issues have also been introduced; Wacker and Sprague (1995) have shown that companies belonging to countries with different cultures differ in the application of specific practices and that some best practices are specific to certain cultures.

In this work, due to the limitations of the applied methodology (which will be explained later), we will only analyze the following contingencies: demand variability, production system and number of product lines. Thus, we formulate the following research propositions:

RP2a: The impact of forecasting techniques on operational performance is mitigated by demand variability

RP2b: The impact of the use of information in the forecasting process on operational performance is mitigated by demand variability

RP2c: The impact of the use of forecasting in decision-making processes on operational performance is mitigated by demand variability

RP3a: The impact of forecasting techniques on operational performance is mitigated by the production system adopted by the company

RP3b: The impact of the use of information in the forecasting process on operational performance is mitigated by the production system adopted by the company 
RP3c: The impact of the use of forecasting in decision-making processes on operational performance is mitigated by the production system adopted by the company

RP4a: The impact of forecasting techniques on operational performance is mitigated by the number of product lines

RP4b: The impact of the use of information in the forecasting process on operational performance is mitigated by the number of product lines

RP4c: The impact of the use of forecasting in decision-making processes on operational performance is mitigated by the number of product lines

Finally, we will consider the configurational perspective. As mentioned previously, some studies have suggested that forecasting should be analyzed by examining specific combinations of variables (Armstrong, 1987; Fildes and Hastings, 1994; Mentzer et al., 1999). Several researchers have also noted that acting simultaneously on the different elements of the forecasting process (i.e., forecasting technique, information collected, etc.) is essential for improving the forecasting process (Lapide, 1999; Helms et al., 2000; Aviv, 2001; McCarthy and Golicic, 2002). In part, this improvement is also related to the companies' willingness to apply consistent practices (Zotteri and Kalchschmidt; 2007). Danese and Kalchschmidt (2010b) have provided evidence that synergistic effects among forecasting practices influence companies' performances. Their results support the configurational perspective, which suggests that companies should design their forecasting process with cohesion in mind. Some authors have suggested specific ideal-types that companies could refer to while designing their forecasting processes (Mentzer et al., 1999; Moon et al., 2003). For these scholars, a different performance will result according to the processes companies adopt. In this work, we will consider a specific classification system of forecasting configurations. More specifically, Mentzer et al. (1999) and Moon et al. (2003) define four possible stages at which forecasting practices can be found: i) functional integration; ii) approach; iii) systems; and iv) performance measurement. These stages are characterized by the different degrees of complexity in forecasting practices, starting from stage one (where a simpler approach is considered) to stage four (where a complex and formal process is defined). For the sake of brevity, we refer to Mentzer et al. (1999) and Moon et al. (2003) for the detailed description 
of these stages. Zotteri and Kalchschmidt (2007) have provided evidence that configurations may be identified using similar variables (e.g., forecasting approach, information collected and use of forecasting in decision-making).

Following our analysis, we formulate the following research proposition;

\section{RP5: Different ideal-types will be associated with different operational performances}

\section{Research methodology}

Analyses were conducted using data collected by the Global Manufacturing Research Group (GMRG). The GMRG has gathered an extensive amount of data regarding manufacturing practices in countries all over the world. The data was collected through a questionnaire distributed simultaneously in different countries by local research groups. The responses are gathered in a unique database (Lindberg et al., 1998). The questionnaire is designed around different modules, each of which focuses on a specific research topic (e.g., outsourcing, manufacturing information systems, purchasing, forecasting). Data on sales forecasting has been collected from 721 companies around the world. Data provided by 503 companies will suffice for the purposes of this paper. Table 1 provides the sample size for each country. The sample is distributed by different companies' sizes; most of the companies are medium-sized companies, but small- and large-sized companies are also represented (see table 2). Different industrial sectors are represented, although all companies listed belong to the manufacturing and assembly industries. In particular, companies in the sample are mainly operating in i) fabricated metal products, ii) industrial and commercial machinery and computer equipment, iii) food and kindred products, iv) electronics and other electrical equipment and components, with the exception of computer equipment and v) textile mill products. Table 3 provides the distribution of the sample by the different industries.

\begin{tabular}{|l|l|l|l|l|}
\hline Country & $\mathbf{\%}$ & & Country & $\mathbf{\%}$ \\
\hline Albania & 2,9 & & Macedonia & 7,5 \\
\hline Austria & 3,3 & & Mexico & 20,1 \\
\hline Croatia & 15,7 & & Poland & 10,9 \\
\hline Hungary & 10,2 & & Sweden & 6,1 \\
\hline Ireland & 7,1 & & Switzerland & 5,9 \\
\hline Italy & 10,3 & & & \\
\hline
\end{tabular}

Table 1 Sample distribution - country

\footnotetext{
* Copy of the questionnaire can be found at http://www.gmrg.org. Appendix A reports the questions considered in the analyses
} 


\begin{tabular}{|l|l|}
\hline Company size & \% \\
\hline Small (n. Employees < 50) & $32,9 \%$ \\
\hline Medium (n. Employees 50 - 250) & $42,9 \%$ \\
\hline Large (n. Employees > 50) & $24,2 \%$ \\
\hline
\end{tabular}

Table 2 Sample distribution - size

\begin{tabular}{|l|r|}
\hline Company size & $\%$ \\
\hline Fabricated metal products, except machinery and transportation equipment & $15 \%$ \\
\hline Industrial and commercial machinery and computer equipment & $11 \%$ \\
\hline Food and kindred products & $9 \%$ \\
\hline Electronic and other electrical equipment and components, except computer equipment & $8 \%$ \\
\hline Textile mill products & $7 \%$ \\
\hline Miscellaneous manufacturing industries & $6 \%$ \\
\hline Furniture and fixtures & $5 \%$ \\
\hline Rubber and miscellaneous plastics products & $5 \%$ \\
\hline Stone, clay, glass, and concrete products & $5 \%$ \\
\hline Chemicals and allied products & $4 \%$ \\
\hline Measuring, analyzing, and controlling instruments; photographic, medical and optical goods; watches & $4 \%$ \\
and clocks & \\
\hline Manufacture of motor vehicles, trailers and semi-trailers & $3 \%$ \\
\hline Paper and allied products & $3 \%$ \\
\hline Apparel and other finished products made from fabrics and similar materials & $2 \%$ \\
\hline Lumber and wood products, except furniture & $2 \%$ \\
\hline Manufacture of other transport equipment & $2 \%$ \\
\hline Printing, publishing, and allied industries & $2 \%$ \\
\hline Leather and leather products & $1 \%$ \\
\hline Petroleum refining and related industries & $1 \%$ \\
\hline Primary metal industries & $1 \%$ \\
\hline
\end{tabular}

Table 3 Sample distribution - industry

In order to test our propositions, we first defined the variables used for the investigation. We considered the industrial sector, the geographical location and the company size as control variables.

Following our review of the literature, we decided to focus our attention on three contingent variables: the demand variability, the production system and the number of product lines. In order to evaluate demand variability, companies were asked to provide information regarding demand in a peak month and demand in a trough month. We defined demand variability as the difference of these two values. Thus, we are not really measuring the demand variability but rather the demand range. We consider this approximation acceptable and consistent with what previous publications have already done (e.g., Zotteri and Kalchschmidt, 2007; Danese and Kalchschmidt, 2010b).

In order to evaluate the production system, companies were asked to provide information regarding the percentage of orders managed by engineering-to-order (ETO), assemble-toorder (ATO), make-to-order (MTO) and make-to-stock (MTS), respectively. 
Lastly, companies were asked to provide information regarding the number of product lines that they were actually managing.

In order to measure the adoption of forecasting techniques, we asked respondents to describe the extent to which their companies used the following: (1) quantitative time series models (e.g., exponential smoothing), (2) quantitative causal models (e.g., regression or econometric analysis) and (3) qualitative models (e.g., market survey or sales quota). In the questionnaire, examples were provided for each category to avoid confusion and reduce interpretation errors. Exponential smoothing and regression/econometric analysis are common examples of time series and causal model techniques, while market surveys and sales quota analyses are usually considered market research tools for qualitative forecasting (Wacker and Sprague 1995; Mentzer and Bienstock, 1998). The three categories are correlated with each other (all Pearson Correlation indexes are above 0.30 and significant at a 0.01 level).

With regard to the market information collected and used by each company, we asked the respondents to what extent each of the following was incorporated into the company's forecast: (1) current economic conditions, (2) customers' sales plans and (3) market research. The three items are correlated with each other (all Pearson correlation indexes are above 0.30, and all are significant at 0.01 level).

Finally, the impact of forecast adoption on the decision-making process was measured by asking respondents to describe to what extent forecasts were used for the following purposes: (1) sales and budget preparation and (2) production planning. The two items are correlated with each other (Pearson correlation index is 0.57 and significant at 0.01 level).

In order to assess the convergent validity and unidimensionality of these three constructs, a confirmatory factor analysis (CFA) was conducted. Marsh et al. (1998) recommended using non-normed fit index (NNFI) and comparative fix index (CFI) together to evaluate model fit. NNFI is 0.97 and CFI is 0.98 , which allows us to consider the model as acceptable (Bentler and Bonett, 1980; Hu and Bentler, 1999). In addition, RMSEA is 0.05, which further suggests that the CFA's overall fit is satisfactory (Hair et al., 2006). Factors loads are significant and exceed 0.40, which is the lower bound of suggested acceptable values (Gefen et al., 2000). Cronbach's Alpha was also measured in order to verify the reliability of each construct (table 3 ). Cronbach $\alpha$-values for the three constructs exceed 0.60 , which indicates high reliability (Nunnally, 1994).

To measure the cost performance, three items were examined. We asked respondents to compare their plant's performance with that of their competitors on a 7-point Likert scale ( 1 is "far worse" and 7 is "far better") in regard to the following costs: (1) direct manufacturing 
costs, (2) total product costs and (3) raw material costs. For delivery performance, a similar question was asked regarding the following factors: (1) order fulfillment speed, (2) delivery speed and (3) delivery as promised. Because comparing performances between companies operating within different contexts is difficult, this research focuses on perceptual and relative measures of cost and delivery performances. Finally, NNFI is 0.99, CFI is 1.00, RMSEA is 0.00, and Cronbach's Alpha values are significantly above the minimum requirement of 0.60 .

Table 4 summarizes the defined constructs and the associated statistics.

\begin{tabular}{|c|c|c|c|c|}
\hline Construct & Items & Average & $\begin{array}{l}\text { Cronbach's } \\
\text { Alpha }\end{array}$ & Factor loads \\
\hline \multirow{3}{*}{ Technique } & Quantitative time series models adoption & \multirow{3}{*}{3.26} & \multirow{3}{*}{0.70} & 0.503 \\
\hline & Quantitative causal models adoption & & & 0.509 \\
\hline & Qualitative models adoption & & & 0.742 \\
\hline \multirow{3}{*}{ Information } & Current economic conditions & \multirow{3}{*}{4.51} & \multirow{3}{*}{0.68} & 0.500 \\
\hline & Customers' sales plan & & & 0.534 \\
\hline & Market research & & & 0.726 \\
\hline \multirow{2}{*}{ Role } & Sales and budget preparation & \multirow{2}{*}{5.24} & \multirow{2}{*}{0.73} & 0.838 \\
\hline & Production planning & & & 0.683 \\
\hline \multirow{3}{*}{ Cost } & Manufacturing costs (compared to competitors) & \multirow{3}{*}{4.26} & \multirow{3}{*}{0.78} & 0.835 \\
\hline & Product costs (compared to competitors) & & & 0.875 \\
\hline & Raw material costs (compared to competitors) & & & 0.528 \\
\hline \multirow{3}{*}{ Delivery } & Order fulfilment speed (compared to competitors) & \multirow{3}{*}{5.20} & \multirow{3}{*}{0.89} & 0.816 \\
\hline & Delivery speed (compared to competitors) & & & 0.923 \\
\hline & Delivery as promised (compared to competitors) & & & 0.829 \\
\hline
\end{tabular}

Table 4 Summary of the variables considered in the analyses

To test the research propositions, we used multivariate regression analyses. In particular, we adopted a hierarchical approach (Wampold and Freund, 1987) in which control variables were added before independent variables were considered with respect to the specific proposition under consideration. Centered (deviations from the mean) and standardized (mean $=0$ and standard deviation $=1$ ) variables were employed in the regression analyses. Centered variables are employed to mitigate any potential multicollinearity effect (Kleinbaum et al., 1988). Acceptable condition indices and variance inflation factors were found in all of the regressions, which provided evidence that multicollinearity was not a problem. Standardized variables were employed to ensure that differences in scale among the variables did not affect the results. Regression quality was controlled by evaluating the significance of the $\mathrm{R}^{2}$ increase at each step of the procedure and by controlling for the statistical power of our analyses (i.e., the probability of correctly finding a relationship when it exists). To evaluate the statistical power, we checked that the $\mathrm{R}^{2}$ values obtained were consistent with those suggested by Hair et al. (2006) and the values found in other OM studies (Das et al., 2006; Bozarth et al., 2009; Zotteri and Kalchschmidt, 2007). 


\section{RESULTS}

In this section, the results of the statistical analyses we have conducted are reported. Discussion of these results is left for the next section.

\subsection{Universalistic Theory Testing}

In order to test the Universalistic theory propositions, we proceeded as follows. We first considered the effects of the control variables by adding industry dummies, country dummies and the number of total plant employees through a stepwise regression. Then we added the forecasting variables. Table 5 provides the results of the analysis for cost and delivery performances, respectively.

\begin{tabular}{|l|c|c|c|c|c|}
\hline & \multicolumn{2}{|c|}{ Cost performance } & & \multicolumn{2}{c|}{ Delivery performance } \\
\hline & $\beta$ & $\Delta \mathrm{R}^{2(1)}$ & & $\beta$ & $\Delta \mathrm{R}^{2(1)}$ \\
\hline Control variables & & $0.123^{* *}(0.116)$ & & & $0.038^{* *}(0.032)$ \\
\hline Forecasting variables & & $0.028^{* *}(0.023)$ & & & $0.040^{* *}(0.034)$ \\
\hline Technique & 0.034 & & & 0.089 & \\
\hline Information & 0.050 & & & $0.129^{*}$ & \\
\hline Role & $0.120^{*}$ & & & 0.026 & \\
\hline & & & & & \\
\hline Full equation & & $0.151^{* *}(0.139)$ & & & $0.078^{* *}(0.066)$ \\
\hline
\end{tabular}

Table 5. Results of regression analyses for the universalistic perspective $\left({ }^{\circ} \mathrm{sig} .<0.1,{ }^{*}\right.$ sig. $<$ $0.05, * *$ sig. $<0.01)$. For control variables we omit the detail of estimate. ${ }^{(1)}$ Adjusted $R^{2}$ in parentheses.

As the results suggest, the variables that were tested have a limited effect on cost performance. More specifically, the extent to which forecasting is used in the decision-making process seems to be associated with better cost performance, while technique and information appear to be irrelevant to cost performance. However, information collection seems to correlate positively with delivery performance. One interesting conclusion of our study is that technique does not seem to have a significant impact on either performance measure. This result supports previous studies that have highlighted the importance of considering other issues besides forecasting techniques (Peterson, 1990; Mentzer and Kahn, 1995; Wacker and Sprague, 1998).

\subsection{Contingency Theory Testing}

In order to test the Contingency theory propositions, we proceeded as follows. After testing the control variables, we ran six different regression analyses for each of the different contingency factors considered in our study (i.e., variability, MTS, ATO, MTO, ETO and number of product lines). Joint effects were considered to test the existence of contingency 
effects. Tables $6,7,8,9,10$ and 11 show the results for testing the different contingency variables.

\begin{tabular}{|l|c|c|c|c|c|}
\hline & \multicolumn{2}{|c|}{ Cost performance } & & \multicolumn{2}{c|}{ Delivery performance } \\
\hline & $\beta$ & $\Delta \mathrm{R}^{2(1)}$ & & $\beta$ & $\Delta \mathrm{R}^{2(1)}$ \\
\hline Control variables & & & & & \\
\hline Demand range & & $0.142^{* *}(0.134)$ & & & $0.055^{* *}(0.045)$ \\
\hline Forecasting variables & & $0.025^{* *}(0.019)$ & & & $0.044^{* *}(0.081)$ \\
\hline 1. Technique & 0.034 & & & 0.096 & \\
\hline 2. Information & 0.023 & & & $0.131^{*}$ & \\
\hline 3. Role & $0.130^{*}$ & & & 0.025 & \\
\hline Interaction & & $0.002(-0.005)$ & & & $0.001(-0.007)$ \\
\hline Demand range x 1 & -0.022 & & & 0.001 & \\
\hline Demand range $\mathrm{x} 2$ & -0.071 & & & 0.064 & \\
\hline Demand range $\mathrm{x} 3$ & 0.216 & & & 0.088 & \\
\hline & & & & & \\
\hline Full equation & & $0.169^{* *}(0.148)$ & & & $0.100^{* *}(0.074)$ \\
\hline
\end{tabular}

Table 6. Results of regression analyses for the contingency perspective-demand range ( ${ }^{\circ}$ sig. $<0.1,{ }^{*}$ sig. $<0.05, * *$ sig. $\left.<0.01\right)$. For control variables we omit the detail of estimate. ${ }^{(1)}$ Adjusted $R^{2}$ in parentheses.

\begin{tabular}{|l|c|c|c|c|c|}
\hline & \multicolumn{2}{|c|}{ Cost performance } & \multicolumn{2}{c|}{ Delivery performance } \\
\hline & $\beta$ & $\Delta \mathrm{R}^{2(1)}$ & & $\beta$ & $\Delta \mathrm{R}^{2(1)}$ \\
\hline Control variables & & & & & \\
\hline MTS & & $0.164^{* *}(0.152)$ & & & $0.059^{* *}(0.048)$ \\
\hline Forecasting variables & & $0.018^{*}(0.012)$ & & & $0.026^{*}(0.017)$ \\
\hline 1. Technique & 0.014 & & & 0.096 & \\
\hline 2. Information & 0.040 & & & $0.131^{*}$ & \\
\hline 3. Role & $0.108^{*}$ & & & 0.025 & \\
\hline Interaction & & $0.009(0.002)$ & & & $0.006(-0.003)$ \\
\hline MTS x 1 & 0.189 & & & 0.001 & \\
\hline MTS x 2 & 0.130 & & & 0.064 & \\
\hline MTS x 3 & -0.339 & & & & \\
\hline & & & & & \\
\hline Full equation & & $0.191^{* *}(0.166)$ & & & \\
\hline
\end{tabular}

Table 7. Results of regression analyses for the contingency perspective-Make To Stock ${ }^{\circ}$ sig. $<0.1, *$ sig. $<0.05, * *$ sig. $<0.01)$. For control variables we omit the detail of estimate. (1) Adjusted $R^{2}$ in parentheses. 


\begin{tabular}{|l|l|c|l|c|c|}
\hline & \multicolumn{2}{|c|}{ Cost performance } & & \multicolumn{2}{c|}{ Delivery performance } \\
\hline & $\beta$ & $\Delta \mathrm{R}^{2(1)}$ & & $\beta$ & $\Delta \mathrm{R}^{2(1)}$ \\
\hline Control variables & & & & & \\
\hline ATO & & $0.156^{* *}(0.143)$ & & & $0.062^{* *}(0.049)$ \\
\hline Forecasting variables & & $0.025^{*}(0.018)$ & & & $0.029^{*}(0.019)$ \\
\hline 1. Technique & 0.025 & & & 0.070 & \\
\hline 2. Information & 0.054 & & & 0.061 & \\
\hline 3. Role & $0.115^{*}$ & & & 0.090 & \\
\hline Interaction & & $0.016^{\circ}(0.009)$ & & & $0.001(-0.008)$ \\
\hline ATO x 1 & 0.260 & & & 0.045 & \\
\hline ATO x 2 & 0.110 & & & -0.067 & \\
\hline ATO x 3 & $-0.461^{*}$ & & & 0.084 & \\
\hline & & & & & $0.092^{* *}(0.060)$ \\
\hline Full equation & & $0.197^{* *}(0.170)$ & & & \\
\hline
\end{tabular}

Table 8. Results of regression analyses for the contingency perspective-Assemble To Order ( sig. $<0.1, *$ sig. $<0.05, * *$ sig. $<0.01)$. For control variables we omit the detail of estimate. ${ }^{(1)}$ Adjusted $R^{2}$ in parentheses.

\begin{tabular}{|l|l|l|l|l|l|}
\hline & \multicolumn{2}{|c|}{ Cost performance } & & \multicolumn{2}{c|}{ Delivery performance } \\
\hline & $\beta$ & $\Delta \mathrm{R}^{2(1)}$ & & $\beta$ & $\Delta \mathrm{R}^{2(1)}$ \\
\hline Control variables & & & & & \\
\hline MTO & & $0.135^{* *}(0.124)$ & & & $0.057^{* *}(0.046)$ \\
\hline Forecasting variables & & $0.022^{*}(0.015)$ & & & $0.036^{* *}(0.028)$ \\
\hline 1. Technique & 0.038 & & & $0.116^{\circ}$ & \\
\hline 2. Information & 0.034 & & & 0.074 & \\
\hline 3. Role & $0.111^{*}$ & & & 0.056 & \\
\hline Interaction & & $0.004(-0.002)$ & & & $0.008(-0.001)$ \\
\hline MTO x 1 & -0.065 & & & 0.090 & \\
\hline MTO x 2 & -0.210 & & & 0.079 & \\
\hline MTO x 3 & 0.172 & & & $-0.365^{\circ}$ & \\
\hline & & & & & \\
\hline Full equation & & $0.161^{* *}(0.137)$ & & & $0.101^{* *}(0.073)$ \\
\hline
\end{tabular}

Table 9. Results of regression analyses for the contingency perspective-Make To Order ${ }^{\circ}$ sig. $<0.1, *$ sig. $<0.05, * *$ sig. $<0.01)$. For control variables we omit the detail of estimate. (1) Adjusted $R^{2}$ in parentheses. 


\begin{tabular}{|l|l|c|c|c|c|}
\hline & \multicolumn{2}{|c|}{ Cost performance } & & \multicolumn{2}{c|}{ Delivery performance } \\
\hline & $\beta$ & $\Delta \mathrm{R}^{2(1)}$ & & $\beta$ & $\Delta \mathrm{R}^{2(1)}$ \\
\hline Control variables & & & & & \\
\hline ETO & & $0.135^{* *}(0.119)$ & & & $0.064^{* *}(0.051)$ \\
\hline Forecasting variables & & $0.020^{*}(0.013)$ & & & $0.031^{*}(0.021)$ \\
\hline 1. Technique & 0.021 & & & 0.087 & \\
\hline 2. Information & 0.046 & & & 0.054 & \\
\hline 3. Role & $0.110^{\circ}$ & & & 0.093 & \\
\hline Interaction & & $0.005(-0.003)$ & & & $0.028^{*}(-0.019)$ \\
\hline ETO x 1 & -0.189 & & & -0.197 & \\
\hline ETO x 2 & 0.067 & & & $0.433^{\circ}$ & \\
\hline ETO x 3 & 0.048 & & & $-0.489^{*}$ & \\
\hline & & & & & \\
\hline Full equation & & $0.160^{* *}(0.129)$ & & & $0.123^{* *}(0.092)$ \\
\hline
\end{tabular}

Table 10. Results of regression analyses for the contingency perspective - Engineering To Order ( sig. $<0.1, *$ sig. $<0.05, * *$ sig. $<0.01)$. For control variables we omit the detail of estimate. ${ }^{(1)}$ Adjusted $R^{2}$ in parentheses.

\begin{tabular}{|l|l|c|c|c|c|}
\hline & \multicolumn{2}{|c|}{ Cost performance } & & \multicolumn{2}{c|}{ Delivery performance } \\
\hline & $\beta$ & $\Delta \mathrm{R}^{2(1)}$ & & $\beta$ & $\Delta \mathrm{R}^{2(1)}$ \\
\hline Control variables & & & & & \\
\hline n. of product lines & & $0.121^{* *}(0.112)$ & & & $0.062^{* *}(0.049)$ \\
\hline Forecasting variables & & $0.032^{*}(0.027)$ & & & $0.032^{* *}(0.025)$ \\
\hline 1. Technique & 0.037 & & & 0.081 & \\
\hline 2. Information & 0.060 & & & $0.136^{*}$ & \\
\hline 3. Role & $0.125^{*}$ & & & 0.011 & \\
\hline Interaction & & $0.002(-0.005)$ & & & $0.009(0.002)$ \\
\hline n. of prod. lines x 1 & 0.048 & & & 0.147 & \\
\hline n. of prod. lines x 2 & -0.143 & & & $-0.349^{\circ}$ & \\
\hline n. of prod. lines x 3 & 0.134 & & & -0.020 & \\
\hline & & & & & \\
\hline Full equation & & $0.155^{* *}(0.134)$ & & & $0.103^{* *}(0.076)$ \\
\hline
\end{tabular}

Table 11. Results of regression analyses for the contingency perspective $-n$. of product lines

$$
\begin{gathered}
(\text { sig. }<0.1, * \text { sig. }<0.05, * * \text { sig. }<0.01) . \text { For control variables we omit the detail of } \\
\text { estimate. }{ }^{(1)} \text { Adjusted } R^{2} \text { in parentheses. }
\end{gathered}
$$

Contingency factors seem to play some role in mitigating the relationships considered in our study. In particular, production system type is influential only in affecting delivery performance. In fact, within ETO contexts there seems to be a positive effect of information. This result indicates that data collection has a beneficial effect within the ETO contexts but a limited impact within other contexts. In addition, within ETO contexts there is negative effect of role, which indicates that leveraging too much on forecasting for decision-making processes may not pay off in this context. This result is not surprising because forecasting is usually more crucial within MTS or ATO contexts than in ETO situations. 
Similar to the results of previous research (i.e., Danese and Kalchschmidt, 2010b), demand variability doesn't seem to be relevant in defining the relationships under investigation.

Lastly, the impact of the number of product lines seems to be limited only to the use of information.

\subsection{Configurational Theory Testing}

To test the configurational theory proposition, we first had to define configurations. Previous contributions have identified many different potential configurations for forecasting practices. In order to identify possible configurations, we ran a two-step cluster analysis based on the forecasting variables. Following Mentzer et al. (1999), we imposed 4 as a cluster number to identify configurations that could be related to previously identified configurations. The four clusters were significant ( $t$ test was significant on all variables with $\mathrm{p}<0.05$ ). Table 12 provides a description of the different clusters identified by our study. Clusters were named according to Mentzer et al. (1999)'s classification system.

\begin{tabular}{|l|l|l|l|l|}
\hline Cluster & n. & Technique & Information & Role \\
\hline Stage 1 & 85 & 1,89 & 3,20 & 3,15 \\
\hline Stage 2 & 127 & 2,36 & 3,79 & 5,83 \\
\hline Stage 3 & 92 & 3,81 & 4,74 & 4,42 \\
\hline Stage 4 & 148 & 4,55 & 5,77 & 6,45 \\
\hline
\end{tabular}

Table 12 Cluster analysis for configurations - centroid description (average values)

The four clusters represented quite well each of the theoretical stages. The only exception is Stage 3; although it represents companies that put significant effort into the adoption of forecasting techniques and information collection, Stage 3 was characterized by a limited adoption of forecasting in the decision-making process.

The chi square test provides no evidence that the clusters are distributed differently for each industrial sector, while some differences can be found among the different countries, although no specific pattern can be identified.

Based on the clusters identified by our study, we adopted a multivariate regression analysis with cost and delivery performances as dependent variables. First, we tested the effects of the control variables by adding regression industry dummies, country dummies and the number of total plant employees through a stepwise regression. Then we added the cluster membership variable to the regression and built four models, one for each cluster. Table 13 provides the results of the analysis. 


\begin{tabular}{|l|c|c|c|c|c|}
\hline & \multicolumn{2}{|c|}{ Cost performance } & & \multicolumn{2}{c|}{ Delivery performance } \\
\hline & $\beta$ & $\Delta \mathrm{R}^{2(1)}$ & & $\beta$ & $\Delta \mathrm{R}^{2(1)}$ \\
\hline Control variables & & $0.123^{* *}(0.116)$ & & & $0.058^{* *}(0.049)$ \\
\hline & & & & & \\
\hline Stage 1 & $-0.095^{*}$ & $0.008^{*}(0.007)$ & & $-0.134^{* *}$ & $0.018^{* *}(0.015)$ \\
\hline & & & & & \\
\hline Stage 2 & -0.017 & $0.000(-0.001)$ & & -0.053 & $0.003(0.000)$ \\
\hline & & & & & \\
\hline Stage 3 & -0.069 & $0.004(0.003)$ & & 0.017 & $0.001(-0.003)$ \\
\hline & & & & & \\
\hline Stage 4 & $0.156^{* *}$ & $0.024^{* *}(0.022)$ & & $0.151^{* *}$ & $0.022^{* *}(0.019)$ \\
\hline
\end{tabular}

Table 13 Results of regression analyses for the configurational perspective $\left({ }^{\circ}\right.$ sig. $<0.1$, * sig. $<0.05$, ** sig. $<0.01)$. For control variables we omit the detail of estimate. ${ }^{(1)}$ Adjusted $R^{2}$ in parentheses.

The results show that the configurations of forecasting practices can have an impact on both cost and delivery performance. In particular, Stage 1 seems to be associated with worse performance, while Stage 4 seems to be correlated with better performance. However, the analysis shows that the other stages are associated with limited impact on both cost and delivery performance.

\section{DISCUSSION}

The results show that all three perspectives have varying degrees of support. The universalistic perspective seems to have some support, although forecasting techniques have no impact on either performance measure. We can argue, however, that this result provides evidence that using structured techniques is not beneficial per se, but they have also to be applied effectively. While we were not able to measure the extent to which companies were capable of effectively applying forecasting techniques, we can still argue that effectively applying simple techniques may be more productive that using complex methods with limited understanding of their utility. This conclusion follows previous literature that has suggested the importance of keeping forecasting methods as simple as possible (Lawrence et al., 1985; Lawrence et al., 2006). These results provide evidence that paying attention to forecasting is important despite the specific context companies face during their forecasting process. From a managerial perspective, these results suggest that examining the behavior of other companies may provide increased understanding of the effectiveness of each practice. From a research perspective, these results underscore the importance of transferring and disseminating best practices. Even if we argue that specific forecasting techniques, organizational models or forecasting processes cannot be used universally, our results show that the general principles 
seem to hold for all contexts. Our study confirms the benefits of designing and disseminating proper forecasting principles (Armstrong, 2001).

The contingency perspective seems to have some support too, although its usefulness is limited to some specific production systems and the number of product lines. For the contingency perspective, only two forecasting practices (i.e., role and information) are affected, while technique doesn't seem to be relevant. Demand variability doesn't seem to have a contingent effect on the relationships considered in our study. This result is consistent with those of previous works (Danese and Kalchschmidt, 2010a and 2010b). The number of product lines has a moderate impact because there is only a significant joint effect with information. This result shows that companies managing several products have more difficulties in managing forecasting and that more effort has to be spent in information sharing to improve performance. This conclusion suggests that managers should focus on improving information management capabilities when the number of product lines increases to prevent any reduction in forecasting effectiveness. Our overall conclusion is that companies' performances are indeed influenced by the variables considered by our study, but only the kind of production system has a strong impact on the variables in question.

Finally, the configurational perspective has some support as well. Our results highlight the importance of having a structured forecasting process, as simple processes tended to be associated with the worst performance measures. However, we must note that even if a complex process is associated with better performances, companies should also design internally coherent systems and thereby distribute investments in the process instead of investing only in one specific aspect (e.g., forecasting methods or information sharing systems). Considering all the elements that constitute how forecasts are derived, our conclusion underscores the importance of benchmarking the overall forecasting process. Often, companies consider improvements on forecasting practices as separate forms of leverage on which they can act. Our results suggest that companies consider forecasting as a bundle of solutions that have to be designed and managed comprehensively. This conclusion is also important because it provides empirical support to previous works (i.e. Moon et al., 2003 ) that until now have received limited empirical evidence. The interpretation of the configurational results doesn't allow us to argue for multiple, equally effective forecasting configurations. We believe that investigating whether or not different solutions may be applied in the same situation would be an important source of future research from a managerial point of view as well. 
In sum, we can state that the external environment influences how forecasting is conducted. Companies that invest in best practices with both the external context (i.e., the production system and the forecasting complexity) and the internal context (i.e., the other forecasting practices) in mind can achieve better operational performances. Figure 1 summarizes this result.

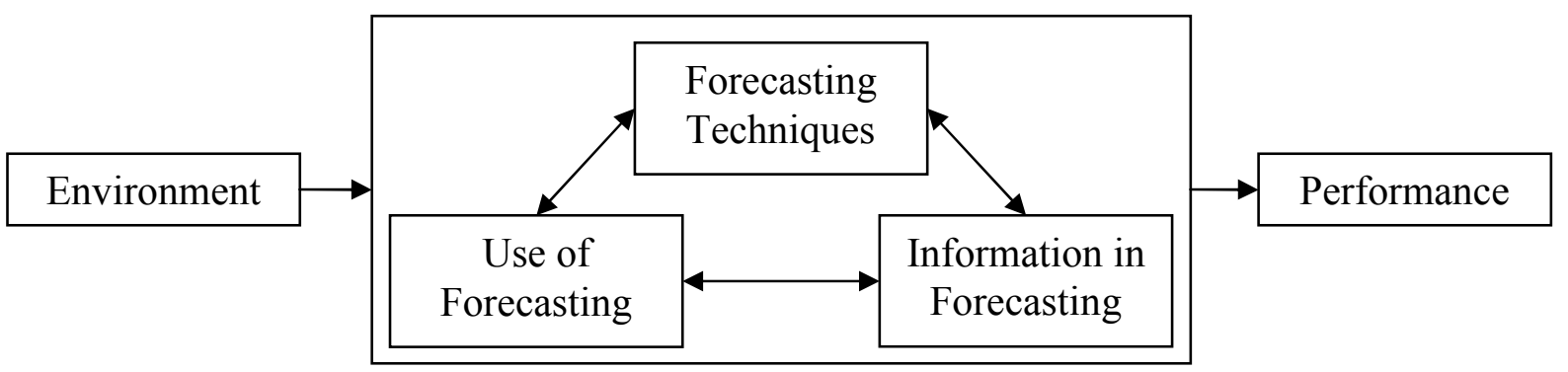

Figure 1. Interaction among the considered variables

\section{CONCLUSIONS}

The purpose of this work was to investigate the theories underlying forecasting practices and their impacts on performance. We have provided evidence that the three different modes of theorizing can be applied, with each partially explaining how forecasting impacts operational performance. To our knowledge, this is the first empirical work that has compared different theories to test their capacity to explain the relationship between forecasting practices and performance. Future studies on forecasting should clearly articulate the perspective that they are using and test their arguments with a methodology that is consistent with the relevant perspective.

This work also contributes to the ongoing research on forecasting effectiveness by studying the relationship between the management of the forecasting process and companies' performances. We argue that this work provides a noteworthy result from a managerial perspective as well because it shows that companies should pay attention to their specific environments even in designing a forecasting system, regardless of the perceived effectiveness of general principles. In addition, companies should focus on designing an internally coherent forecasting system rather than simply relying on forecasting techniques. Lastly, it is important to highlight some limitations of our work. First, we need to consider that the GMRG dataset was not designed to specifically study this topic (the questionnaire addresses several topics, from purchasing to MP\&C), and thus only a limited number of details can be analyzed with the available data. More specifically, because only a limited set of information on the forecasting context could be collected from the questionnaire, other relevant variables could not be analyzed. In particular, future works should pay attention to 
forecasting familiarity and to the competence of the people involved in the forecasting process. In the future, data should be collected with specific regard to this topic so as to deepen the analysis. Second, this work has not been able to assess the explicative power of the different perspectives; that is, we could not discover to what extent the different perspectives were able to explain the phenomenon under consideration.

Aside from these limitations, we consider this work relevant for both researchers and practitioners because it contributes to the vast debate on how companies should design their forecasting systems.

\section{REFERENCES}

Armstrong, J.S., 1987. The forecasting audit. In: Makridakis, S., Wheelwright, S.C. (Eds.). The handbook of forecasting, John Wiley, New York, 584-602.

Armstrong, J.S., 2001. Principles of Forecasting: A Handbook for researchers and practitioners. Kluwer, Boston.

Aviv, Y., 2001, The effect of Collaborative Forecasting on Supply Chain Performance, Management Science, 47(10), 1326-1343.

Bartezzaghi, E., Verganti, R., 1995. Managing demand uncertainty through order overlapping. International Journal of Production Economics 40, 107-120.

Bentler, P.M., Bonett, D.G., 1980, Significance tests and goodness of fit in the analysis of covariance structures, Psychological Bulletin, 88, 588-606.

Bozarth C., McDermott C., 1998. Configurations in manufacturing strategy: a review and directions for future research. Journal of Operations Management, 16: 427-439.

Bozarth, C.C., Warsing, D.P., Flynn, B.B., Flynn, E.J., 2009. The impact of supply chain complexity on manufacturing plant performance. Journal of Operations Management 27, 78-93.

Cerullo, M.J., Avila, A., 1975, Sales forecasting practice - a survey, Managerial Planning, vol. 24, n. $2,33-39$

Chaman, L.J., 1999, Ten commandments of selling forecasts to forecast users, Journal of Business Forecasting Methods \& Systems 17(4), 2-5.

Chaman, L.J., 2001, Forecasting Practices in Corporate America, Journal of Business Forecasting Methods \& Systems 20(2), 2-4.

Chaman, L.J. 2004, Business forecasting practices in 2003, Journal of Business Forecasting, Fall, 2-6. 
Chase, C., 1999, Sales forecasting at the dawn of the new millennium?, Journal of Business Forecasting Methods \& Systems 18 (3), 2-5.

Dalrymple, D.J., 1987. Sales forecasting practices: Results of a United States survey. International Journal of Forecasting 3, 379-392.

Danese, P., Kalchschmidt M., 2010a, The role of the forecasting process in improving forecast accuracy and operational performance, International Journal of Production Economics, doi:10.1016/j.ijpe.2010.09.006

Danese, P., Kalchschmidt M., 2010b, The impact of forecasting on companies' performance: Analysis in a multivariate setting, International Journal of Production Economics, doi:10.1016/j.ijpe.2010.04.016

Das, A., Narasimhan, R., Talluri, S., 2006. Supplier integration - Finding an optimal configuration. Journal of Operations Management 24, 563-582.

Dekker, M., Donselaar, K. Ouwehand, P., 2004, How to use aggregation and combined forecasting to improve seasonal demand forecasts, International Journal of Production Economics, 90, 151-167

Delery J.E., Doty D.H. 1996, Modes of theorizing in strategic human resource management: test of universalistic, contingency and configurational performance predictions, Academy of Management Journal, 39 (4), 802-835

Dewar, R, 1979, Universalistic and Contingency Predictions of Employee Satisfaction and Conflict, Administrative Science Quarterly, 24 (3), 426-448

Diamantopoulos, A., Winklhofer, H., 1999, The impact of firm and export characteristics on the accuracy of export sales forecasts: evidence from UK exporters, International Journal of Forecasting, 15, 67-81.

Fildes, R, Hastings, R., 1994. The organization and improvement of market forecasting. Journal of the Operational Research Society 45, 1- 16.

Fildes, R., Goodwin, P., 2007, Against your better judgment? How organizations can improve their use of management judgment in forecasting, Interfaces, vol. 37, n. 6, 570

Gefen, D., Straub, D., Boudreau, M., 2000, Structural equation modeling and regression: guidelines for research practice, Communications of AIS, 4 (7), 1-76.

Hair, J. F. Jr., Black, W. C., Babin B.J., Anderson, R. E., Tatham, R. L. , 2006, Multivariate Data Analysis, 6th edn. New York: Macmillan

Helms, M.M., Ettkin, L.P., Chapman, S., 2000, Supply chain forecasting: Collaborative forecasting supports supply chain management, Business Process Management Journal 6(5), 392-407. 
Hu, L., Bentler, P.M., 1999, Cutoff Criteria for Fit Indexes in Covariance Structure Analysis: Conventional Criteria versus New Alternatives, Structural Equation Modeling, 6 (1), 1-55

Hughes, M.C., 2001, Forecasting practice: organisational issues, Journal of the Operational Research Society, 52(2), 143-149.

Kahn KB, Mentzer JT, 1994, The impact of team-based forecasting, Journal of Business Forecasting, Summer: 18-21.

Kahn KB, Mentzer JT, 1995, Forecasting in consumer and industrial markets, Journal of Business Forecasting, 14 (2): 21-28.

Ketokivi M, Schroeder R, 2004, Manufacturing practices, strategic fit and performance: A routine-based view, International Journal of Operations \& Production Management, 24 (2): $171-191$

Klassen, R.D., Flores, B.E., 2001, Forecasting practices of Canadian firms: Survey results and comparisons, International Journal of Production Economics, 70, 163-174.

Kleinbaum, D.G., Kupper, L.L., Muller, K.E., 1988, Applied Regression Analysis and Other Multivariate Models, PWS-Kent Publishing, Boston.

Lapide, L., 1999, How about collaborative forecasting?, Journal of Business Forecasting Methods \& Systems 18(3), 24-25.

Laugen, B.T., Acur, N., Boer, H., Frick, J., 2005, Best manufacturing practices. What do bestperforming companies do?, International Journal of Operations and Production Management, 25 (2), 131-150.

Lawrence, M., Edmundson, R., \& O’Connor, M., 1985, An examination of the accuracy of judgmental extrapolation of time series. International Journal of Forecasting, 1, 25- 35

Lawrence M., Goodwin P., O’Connor M., Onkal, D., 2006, Judgmental forecasting: A review of progress over the last 25 years, International Journal of Forecasting, 22, 493-518

Lawrence, M., O’Connor, M., Edmundson, B., 2000. A field study of sales forecasting accuracy and processes. European Journal of Operational Research 122, 151-160.

Mady, M.T., 2000, Sales forecasting practices of Egyptian public enterprises: Survey evidence, International Journal of Forecasting, vol. 16, n. 3, 359-368

Makridakis, S., Wheelwright, S.C., Hyndman, R.J., 1998, Forecasting: Methods and Applications, Wiley.

Marsh, H.W., Balla, J.R. and McDonald, R.P., 1988, Goodness-of-fit indexes in confirmatory factor analysis: the effect of sample size, Psychological Bulletin, 103, pp. 391-410 
McCarthy, T.M., Golicic, S.L., 2002, Implementing collaborative forecasting to improve supply chain performance, International Journal of Physical Distribution \& Logistics Management, 32(6), 431-454.

McCarthy, I. P., Tsinopoulos, C., Allen, P. and Rose-Anderssen, C., 2006, New Product Development as a Complex Adaptive System of Decisions. Journal of Product Innovation Management, 23: 437-456

McCarty, I.P., Lawrence, T.B., Wixted, B., Gordon, B.R., 2010, A Multidimensional Conceptualization of Environmental Velocity, The Academy of Management Review, 35 (4): $604-626$

Mentzer, J.T., Bienstock, C., 1998. Sales Forecasting Management, Sage Publications, London.

Mentzer, J.T., Cox, J.E., 1984. Familiarity, applications, and performance of sale forecasting techniques. Journal of Forecasting 3, 27-36.

Mentzer, J.T., Kahn, K.B., 1995. Forecasting technique familiarity, satisfaction, usage and application. Journal of Forecasting 14 (5), 465-476.

Mentzer, J.T, Kahn, 1997. Sales Forecasting Systems in corporate America. Journal of Business Forecasting Methods \& Systems 16 (1), 6-12.

Mentzer, J.T., Bienstock, C., Kahn, K., 1999, Benchmarking Sales Forecasting Management, Business Horizons 42(3), 48-56.

Moon, M.A., Mentzer, J.T., 1998, Seven keys to better forecasting, Business Horizons, 41 (5), 44-52.

Moon, M.A., Mentzer, J.T., Smith, C.D., 2003. Conducting a sales forecasting audit. International Journal of Forecasting 19, 5-25.

Nunnally, J.C., 1994. Psychometric Theory, McGraw-Hill, New York

Peterson, R.T., 1990. The role of experts' judgment in sales. Journal of Business Forecasting $9(2), 16-21$

Peterson, R.T., 1993, Forecasting practices in retail industry, Journal of Business Forecasting, $12(1), 11-14$.

Peterson, R.T. Jun, M., 1999, Forecasting sales in wholesale industry, Journal of Business Forecasting Methods \& Systems, Vol. 18 No. 2, pp. 15-17.

Powell, T., 1995, TQM as competitive advantage: a review and empirical study, Strategic Management Journal, 16 (1), 15-37

Reyna, S., Kwong, K.K., Li, C., 1991, Forecasting practices in healthcare industry, The Journal of Business Forecasting Methods and Systems, vol. 10, n. 1, 23 
Sanders, N.R., 1992, Corporate forecasting practices in the manufacturing industry, Production and Inventory Management, 33, 54-57.

Sanders, N., Manrodt, K.B., 1994, Forecasting practices in US corporations: Survey results, Interfaces 24, $92-100$

Sanders, N.R., Ritzman, L.P., 2001. Judgmental adjustment of statistical forecasts. In: Armstrong, J.S., Principles of forecasting: A Handbook for Researchers and Practitioners, Kluwer Academic Publishers.

Småros J., 2007. Forecasting collaboration in the European grocery sector: Observations from a case study. Journal of Operations Management. 25, 702-716.

Sousa, R., Voss, C.A., 2001, Quality management: universal or context-dependent? Production and Operations Management Journal, 10 (4), 383-404.

Sousa, R., Voss, C.A., 2008, Contingency theory in operations management practices, Journal of Operations Management, 26, 697-713.

Stalk, HG.H., Hault, T.M., 1990. Competing Against Time: How Time-Based Competition Is Reshaping Global Markets, Free Press, New York.

Stevens, G.C., 1989. Integration of the Supply Chain. International Journal of Physical Distribution and Materials Management 19(8), 3-8.

Tawfik Mady M., 2000, Sales forecasting practices of Egyptian public enterprises: survey evidence, International Journal of Forecasting, 16 (3): 359-368

Triantis, J.E., 2002. Collaborative Forecasting : an intra-company perspective. The Journal of Business Forecasting, Winter, 13-15

Voss C.A., 2005, Paradigms of manufacturing strategy re-visited, International Journal of Operations and Production Management, 25 (12), 1223-1227.

Wacker JG, Sprague LG, 1995 The impact of institutional factors on forecast accuracy: manufacturing executives perspective, International Journal of Production Research, 33 (11):2945-2958.

Wacker JG, Sprague LG, 1998, Forecasting accuracy: comparing the relative effectiveness of practices between seven developed countries, Journal of Operations Management, 16:27190.

Watson, M.C., 1996, Forecasting in the Scottish electronics industry, International Journal of Forecasting, 12, 361-371.

Winklhofer, H., Diamantopoulos, A., 1997, Organisational aspects of export sales forecasting: an empirical investigation, Journal of Strategic Marketing, 5(3), 167-185. 
Winklhofer, H., Diamantopoulos, A., 2002, A comparison of export sales forecasting practices among UK firms, Industrial Marketing Management, 31, 479-490.

Wisner, J.D., Stanley, L.L., 1994, Forecasting practices for JIT and non-JIT purchasers, European Journal of Purchasing and Supply Management, 1(4), 219-225.

Wright, D.J., Capon, G., Page, R. Quiroga, J., Taseen, A.A., Tomasini, F., 1986. Evaluation of forecasting methods for decision support. International Journal of Forecasting 2(2), 139153.

Zotteri G., Kalchschmidt M., 2007, Forecasting practices: Empirical evidence and a framework for research, International Journal of Production Economics, 108, 84-99

\section{APPENDIX - QUESTIONS INCLUDED IN THE GMRG QUESTIONNAIRE.}

1. To what extent does the company use these techniques for sales forecasting? (Circle one number for each.)

\begin{tabular}{|l|l|c|c|c|c|c|c|c|}
\hline Type & Example(s) & $\begin{array}{c}\text { Not at } \\
\text { all }\end{array}$ & & & $\begin{array}{c}\text { Some } \\
\text {-what }\end{array}$ & & & $\begin{array}{c}\text { A } \\
\text { great } \\
\text { extent }\end{array}$ \\
\hline $\begin{array}{l}\text { SF01. A Quantitative } \\
\text { Time series models }\end{array}$ & $\begin{array}{l}\text { Exponential } \\
\text { Smoothing, Trend, etc. }\end{array}$ & 1 & 2 & 3 & 4 & 5 & 6 & 7 \\
\hline $\begin{array}{l}\text { SF01. B Quantitative } \\
\text { Causal Models }\end{array}$ & $\begin{array}{l}\text { Regression, } \\
\text { Econometric Analysis }\end{array}$ & 1 & 2 & 3 & 4 & 5 & 6 & 7 \\
\hline $\begin{array}{l}\text { SF01. C Qualitative } \\
\text { models }\end{array}$ & $\begin{array}{l}\text { Market Survey, Sales } \\
\text { Quota }\end{array}$ & 1 & 2 & 3 & 4 & 5 & 6 & 7 \\
\hline
\end{tabular}

2. To what extent is each of the following quantitatively combined into the company's forecast? (Circle one number)

\begin{tabular}{|l|c|c|c|c|c|c|c|}
\hline & $\begin{array}{c}\text { Not at } \\
\text { all }\end{array}$ & & & $\begin{array}{c}\text { Some } \\
\text {-what }\end{array}$ & & $\begin{array}{c}\text { A great } \\
\text { extent }\end{array}$ \\
\hline SF02. A current economic conditions & 1 & 2 & 3 & 4 & 5 & 6 & 7 \\
\hline SF02. B customer's numerical sales plans & 1 & 2 & 3 & 4 & 5 & 6 & 7 \\
\hline SF02. C results of market research & 1 & 2 & 3 & 4 & 5 & 6 & 7 \\
\hline
\end{tabular}

3. To what extent is the forecast used for the following purposes? (Circle one number)

\begin{tabular}{|l|c|c|c|c|c|c|c|}
\hline & $\begin{array}{c}\text { Not at } \\
\text { all }\end{array}$ & & $\begin{array}{c}\text { Some } \\
\text {-what }\end{array}$ & & $\begin{array}{c}\text { A great } \\
\text { extent }\end{array}$ \\
\hline SF03.A sales and budget preparation & 1 & 2 & 3 & 4 & 5 & 6 & 7 \\
\hline SF03.B production resource planning & 1 & 2 & 3 & 4 & 5 & 6 & 7 \\
\hline
\end{tabular}

4. Assume a normal demand for a month to be 100 , what would be the:

(IP38) demand level for a "peak" month (e.g., $20 \%$ more than normal $=120$ )

'Peak' Month =

(IP39) demand level for a "trough" month (e.g., $30 \%$ less than normal = 70)

'Trough' Month=

5. For each of the items listed below, how does your plant's performance compare with that of your competitors?

(Circle one number.) 
Far Worse

Competitive

Far better

\begin{tabular}{|l|c|c|c|c|c|c|c|}
\hline CG02 direct manufacturing costs & 1 & 2 & 3 & 4 & 5 & 6 & 7 \\
\hline CG03 total product costs & 1 & 2 & 3 & 4 & 5 & 6 & 7 \\
\hline CG04 raw material costs & 1 & 2 & 3 & 4 & 5 & 6 & 7 \\
\hline CG08 order fulfillment speed & 1 & 2 & 3 & 4 & 5 & 6 & 7 \\
\hline CG09 delivery speed & 1 & 2 & 3 & 4 & 5 & 6 & 7 \\
\hline CG10 delivery as promised & 1 & 2 & 3 & 4 & 5 & 6 & 7 \\
\hline
\end{tabular}

6. DM05 How many product lines or product families does the plant produce? product lines or families

7. IP14 (A, B, C \&D) In this plant, what percent of manufacturing orders fall into these categories? $\%$ Engineer to order $\%$ Made to order $\%$ Assemble to order $\%$ Made to stock 